\title{
Septicaemia Caused by Community Acquired Klebsiella pneumonia Complicated with Endocarditis and Meningoencephalitis: A Case Report
}

Fane MEL ${ }^{1 *}$, Dollo I ${ }^{1}$, Sodqi $M^{1}$, Jebbar $\mathbf{S}^{1}$, Nourredine $\mathrm{K}^{2}$, Oulad Lahsen $\mathrm{A}^{1}$, Chakib $\mathrm{A}^{1}$, Hebba $\mathbf{R}^{1}, \mathrm{Filali}_{\mathrm{KMEL}}{ }^{1}$ and Marih $\mathrm{L}^{1}$

${ }^{1}$ Unit Infectiology Diseases, UHC Ibn Rochd, Casablanca, Morocco

2 Department of Cardiology, UHC Ibn Rochd, Casablanca, Morocco

"Corresponding author: Fane MEL, Unit Infectiology Diseases, UHC Ibn Rochd, Casablanca, Morocco, Tel: +2120660832362; E-mail: elfanemouna@gmail.com

Rec date: May 03, 2016; Acc date: May 28, 2016; Pub date: May 31, 2016

Copyright: @ 2016 Fane MEL, et al. This is an open-access article distributed under the terms of the Creative Commons Attribution License, which permits unrestricted use, distribution, and reproduction in any medium, provided the original author and source are credited.

Abstract
Meningoencephalitis and community endocarditis caused by Klebsiella pneumonia $(K$. pneumonia) is uncommon,
with a poor prognosis. This severity is related to the virulence of the organism. Associated fragile terrain is frequent
and participates in infection prognosis. We report the first Moroccan case involving meningoencephalitis and
community endocarditis $K$. pneumonia in adults with craniofacial trauma and chronic alcoholism history. The history
and clinical data associated with imagery are in favor of a complicated meningitis endocarditis $K$. pneumoniae. The
early management of our patient resulted in a cure without sequelae. This case illustrates the severity of community
acquired $K$. pneumoniae infection. It also helps to emphasize the search of heart and neuromeningeal location in
front of any sepsis related to this germ.

Keywords: Septicaemia; Endocarditis; Meningoencephalitis; Klebsiella pneumonia; Strain community

\section{Introduction}

Klebsiella $(K$.$) pneumoniae is one of the important pathogenic$ members of Enterobactericeae and exists ubiquitously in our environment [1]. Described initially in necrotizing pneumonia and occurring primarily in alchololic patients, actually K. pneumonia is mainly responsible for nosocomial infections. Diabetes mellitus is a usual predisposing factor [2]. However, endocarditis and meningitis associated with community-acquired $K$. pneumoniae infection is rare [3]. In this report, we present a case of endocarditis in which community-acquired $K$. pneumoniae bacteremia involved both mitral and aortic valves associated with meningoencephalitis. The clinical case presented recall epidemiological, microbiological and clinical characteristics of severe K. pneumoniae infection.

\section{Case Report}

A 44 -year-old male presented to the infectious disease unit at Casablanca with acute febrile consciousness disorder. His medical history was significant for a cranio-facial trauma and chronic alcoholism. The patient's mental state was stuporous. On physical examination, the patient had a fever $\left(40^{\circ} \mathrm{C}\right)$ and hypotensive $(100 / 50$ $\mathrm{mmHg}$ ). A systolic murmur was heard at the left sternal border. Transesophageal echocardiography revealed large vegetation involving the posterior aortic valve and small vegetation involving the mitral valve with a moderate regurgitation, an abscess of the posterior wall of the aorta and congenital valvulopathy (bicuspid aortic valve) (Figure 1). Computed tomography of brain showed a fracture of the zygomatic arch and the posterolateral wall of the left maxillary sinus (Figure 2). MRI scan of brain showed multiple small infarctions, most likely from septic embolism (Figure 3). Cerebrospinal fluid (CSF) was xanthochromic. CSF analysis showed 13 cells $/ \mathrm{mm}^{3}$ predominantly polynuclear neutrophils with a hypoglycorachia of $0,01 \mathrm{~g} / \mathrm{L}$ and a protein concentration of $3 \mathrm{~g} / \mathrm{l}$. Gram staining showed no germs on direct examination. The culture of CSF showed heavy growths of Klebsiella pneumoniae which was resistant to ampicillin and piperacillin, but sensitive to all other antibiotics. The same organism was identified in two pairs of aero-anaerobic blood cultures. The WBC count was $15,880 / \mathrm{mL}$, the hemoglobin level was $9.8 \mathrm{~g} / \mathrm{dL}$, the platelet count was $16000 / \mathrm{mL}$ and C-reactive protein was $79 \mathrm{mg} / \mathrm{l}$. The urine culture was sterile. Moreover, viral serologies (virus hepatitis B and C, HIV) and syphilis were negative. The dosage of immunoglobulins G, A and $\mathrm{M}$, Chest radiograph and computed tomography were normal. There was no evidence of endophthalmitis. Intravenous administration of Ceftazidime $100 \mathrm{mg} / \mathrm{kg} /$ day and gentamycin 3 $\mathrm{mg} / \mathrm{kg} /$ day IV for two weeks, then four weeks of only ceftazidime. The antibiotic treatment was supplemented by emergent valve replacement. The evolution was good.

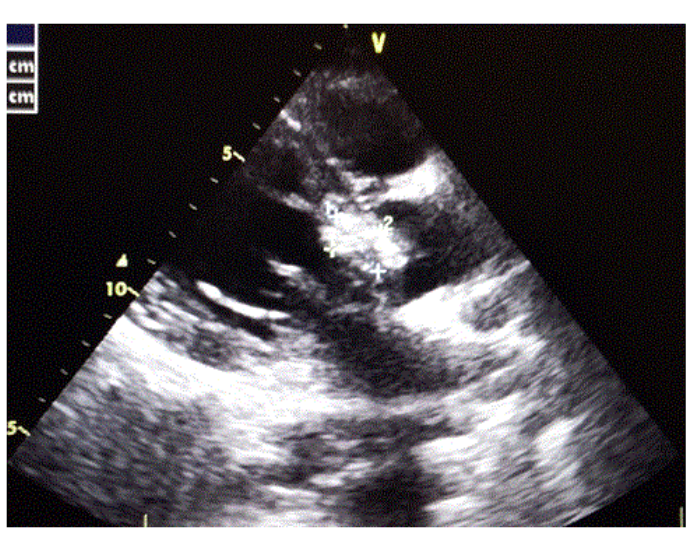

Figure 1: Transesophageal echocardiography showing vegetation magma at the aortic valve. 
Citation: Fane MEL, Dollo I, Sodqi M, Jebbar S, Nourredine K, et al. (2016) Septicaemia Caused by Community Acquired Klebsiella pneumonia Complicated with Endocarditis and Meningoencephalitis: A Case Report. J Cardiovasc Dis Diagn 4: 244. doi: $10.4172 / 2329-9517.1000244$

Page 2 of 3

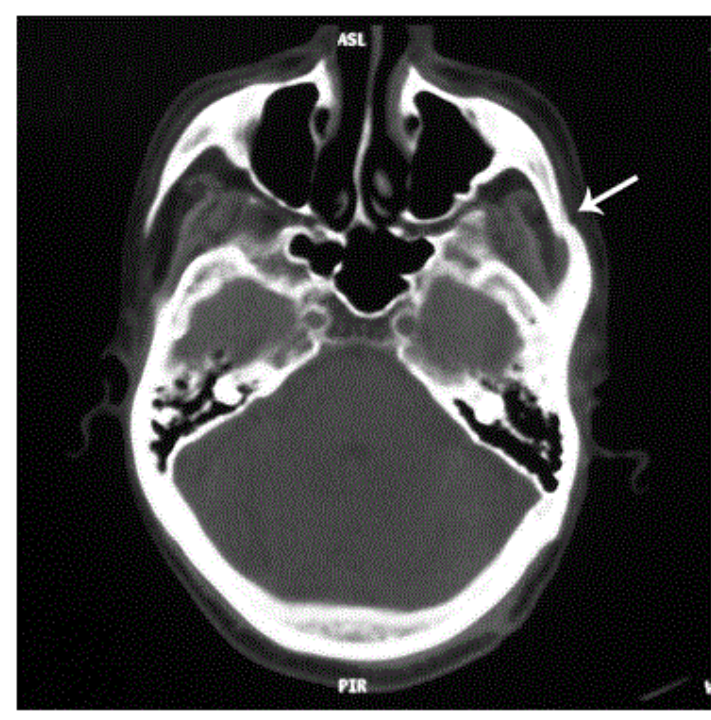

Figure 2: Computed tomography scan of the brain showing a fracture of the zygomatic arch left.

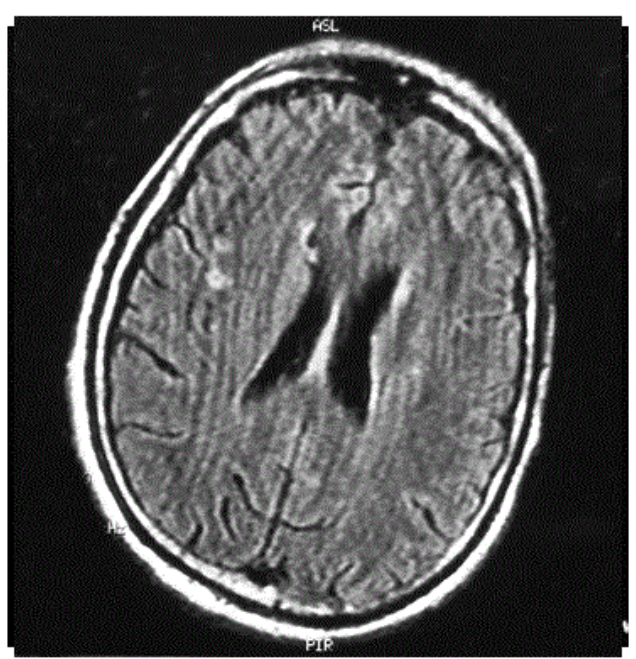

Figure 3: MRI showing nodular brain lesions.

\section{Discussion}

$K$. pneumoniae is responsible of postsurgical nosocomial infections or secondary to invasive procedures. However, this bacterium can also cause community-acquired infections and usually causes chest, urinary, and intra-abdominal infections [1]. It can be, exceptionally, responsible for community-acquired infectious endocarditis in adults; apart from cases described in some countries in Southeast Asia [4]. Aortic disease was more common than mitral disease [5]. This is consistent with the data from our patient. This bacterium can also, rarely, be responsible for community-acquired meningitis in adults. The cases described in Western countries are usually secondary to local invasive procedures [6]. To our knowledge, this is the first case involving meningoencephalitis and Community-acquired infectious endocarditis caused by $K$. pneumoniae reported in Morocco. Much comorbidity such as chronic obstructive bronchitis, liver cirrhosis, diabetes mellitus, neoplasia, asplenia, chronic alcoholism and corticosteroids have been identified as risk factors capable of promoting the development and severity of $K$. pneumoniae infections [7]. Alcoholism is considered a risk factor in our patient. The portal of entry of $K$. pneumoniae bacteremia is identified in only $32 \%$ of cases; it is usually urinary, digestive and hepatobiliary. Other gateways, vascular, oral or lung were rarely found [8]. In Morocco, in both cases of K. pneumoniae meningoencephalitis reported in 2007 and 2008, the portal entry was presumed urinary tract infection [9]. Kallel et al reported in 2006, 5 cases of post traumatic $K$. pneumoniae meningitis in a study of 38 cases [10]. In our patient, the chest $\mathrm{x}$-ray, liver ultrasound and urine analysis have not shown anomalies which could incriminate a gateway to infection. The lack of recent neurosurgical act or hospitalization, the history of head trauma twenty days before admission and presence of infection of the central nervous system has allowed us to evoke that meningitis was the site of initial infection and appears to be the cause of bacteremia with bacterial discharge and graft on asymptomatic congenital valvulopathy (bicuspid aortic valve). The systematic search for septic metastatic sites in case of positive $K$. pneumoniae blood cultures, seem necessary in the light of this case and others reported cases. The treatment of $K$. pneumoniae infectious endocarditis uses antibiotics and surgery in half of the cases. Recent guidelines recommend the combination of a third-generation cephalosporin (TGC) for four to six weeks with an aminoglycoside (gentamicin and amikacin) during the first two weeks. If resistance to TGC, piperacillin-tazobactam, constitues an alternative [11]. Despite advances in diagnostic and therapeutic means, mortality of $K$. pneumoniae infectious endocarditis remains high, estimated at $49 \%$ [12]. In our patient, early and adequate antibiotic treatment completed by surgery helped cure.

\section{Conclusion}

This observation illustrates the trend of this bacterium to give septic transplants, especially in the presence of comorbid conditions and the difficulty of identifying the original site in the presence of several infected sites. On the other hand, it shows the severity of communityacquired B $K$. pneumoniae bacteremia. In our case, an early management of the patient and the wild-type strain had probably contributed to therecovery without neurological sequels.

\section{Conflict of interest}

The authors declare no conflict of interest

\section{References}

1. L'Kassmi H, Chegri M, Mounach J, Amine IL (2008) Meningoencephalitis due to community Klebsiella pneumoniae in an adult immunocompetent: a case report. Ann Biol Clin 66: 566-568.

2. Kassis-Chikhani N (2013) Klebsielle Pneumoniae pathog_ene nosocomial, resistance et virulence.

3. Chang WN, Huang CR, Lu CH, Chien CC (2012) Adult Klebsiella pneumoniae meningitis in Taiwan: an overview. Acta Neurol Taiwan 21: 87-96.

4. Hwang J, Her C, Kim YW (2013) Endocarditis Caused by CommunityAcquired Klebsiella pneumoniae Infection-A Case Report. Korean J Crit Care Med 28: 41-45. 
Citation: Fane MEL, Dollo I, Sodqi M, Jebbar S, Nourredine K, et al. (2016) Septicaemia Caused by Community Acquired Klebsiella pneumonia Complicated with Endocarditis and Meningoencephalitis: A Case Report. J Cardiovasc Dis Diagn 4: 244. doi: $10.4172 / 2329-9517.1000244$

Page 3 of 3

5. Ko WC, Paterson DL, Sagnimeni AJ, Hansen DS, Von Gottberg, et al (2002) Communityacquired Klebsiella pneumoniae bacteremia: global differences in clinical patterns. Emerg Infect Dis 8: 160-166.

6. Giobbia M, Scotton PG, Carniato A, Cruciani M, Farnia A, et al. (2003) Community-acquired Klebsiella pneumoniae bacteremia with meningitis and endophthalmitis in Italy. Int J Infect Dis 7: 234-235.

7. Baudrand H, Ngahane BHM, Marcu M, Freymond N, Pacheco Y, et al (2009) Lung abscess due to community acquired Klebsiella pneumonia. Rev Mal Respir 26: 773-778.

8. Fang CT, Chen YC, Chang SC, Sau WY, Luh KT (2000) Klebsiella pneumoniae meningitis: timing of antimicrobial therapy and prognosis. Q J Med 93: 45-53.

9. Guedari H, Hachimi A, Charra B, Benslama A, Motaouakkil S (2007) Klebsiella pneumoniae meningoencephalitis. Ann Fr Anesth Reanim 26: 1004-1005.
10. Kallel H, Chelly H, Ghorbel M, Bahloul M, Ksibi H, et al. (2006) Posttraumatic meningitis: incidence, bacteriology, and outcomes. Neurochirurgie 52: 397-406.

11. Bellazreg F, Gaillet M, Perronne C, Crémieux AC (2012) Native valve postoperative Klebsiella pneumoniae endocarditis. Med Mal Infect 42: 85-86.

12. Hoen B, Alla F, Selton-Suty C, Béguinot I, Bouvet A, et al. (2002) Changing profile of infective endocarditis: results of a 1-year survey in France. JAMA 288: 75-81.

13. Devlin JW, Al-Qadheeb NS, Chi A, Roberts RJ, Qawi I, et al. (2014) Efficacy and safety of early dexmedetomidine during noninvasive ventilation for patients with acute respiratory failure: a randomized, double-blind, placebo-controlled pilot study. Chest 145: 1204-1212. 